\title{
Risk factors, mortality and acute kidney injury outcomes in cirrhotic patients in the emergency department
}

\author{
Paulo Ricardo Gessolo Lins ${ }^{*}$ (D), Wallace Stwart Carvalho Padilha', Carolina Frade Magalhaes Giradin Pimentel ${ }^{2}$, \\ Marcelo Costa Batista ${ }^{1}$ and Aécio Flávio Teixeira de Gois ${ }^{2}$
}

\begin{abstract}
Background: Acute kidney injury (AKI) is common in cirrhotic patients and is associated with negative outcomes. The aim of this study was to evaluate the presence of AKI and its progression according to KDIGO (Kidney Disease: Improving Global Outcomes) criteria in cirrhotic patients admitted to the emergency department and to determine the association of AKI with hospital mortality.

Methods: This retrospective study included 258 cirrhotic patients admitted to the emergency department of a university hospital from March 2015 to February 2017. AKI was diagnosed and classified according to the KDIGO criteria.

Results: The overall incidence of AKI in cirrhotic patients was 53.9\%, and the overall hospital mortality was $28.4 \%$. Mortality was associated with the presence, stage, and progression of AKI. Patients with AKI stage 1 and $\mathrm{sCr}<1.5 \mathrm{mg} / \mathrm{dl}$ (KDIGO 1a) had a lower mortality rate than patients with AKI stage 1 and $\mathrm{s} C r>1.5 \mathrm{mg} / \mathrm{dl}$ (KDIGO 1b). In the logistic regression analysis, three variables were independently associated with hospital mortality: cancer, AKI and progression of AKI.

Conclusions: According to the data presented, a single measure of creatinine is not enough, and there is a need for meticulous follow-up of the renal function of patients with hepatic cirrhosis hospitalized in an emergency unit. In addition, this study reinforces the need for subclassification of KDIGO 1 in cirrhotic patients, since patients with acute renal injury and creatinine greater than $1.5 \mathrm{mg} / \mathrm{dL}$ present a worse clinical outcome.
\end{abstract}

Keywords: Liver cirrhosis, Acute kidney injury, Hospital mortality, KDIGO, Progression of AKI

\section{Background}

Acute kidney injury (AKI) is a common complication in patients with liver cirrhosis who are admitted to the emergency department, and it is related to significantly higher mortality rates among this population [1-8]. AKI pathogenesis in cirrhotic patients is intimately related to hemodynamic changes secondary to liver failure and to a self-perpetuating process that ultimately leads to renal and splenic vasoconstriction, promoting decoupling

\footnotetext{
*Correspondence: pr.lins@uol.com.br

${ }^{1}$ Discipline of Nephrology, Federal University of São Paulo, Rua Botucatu, 591

- $15^{\circ}$ andar - Cj153 - Vila Clementino, São Paulo, SP 04023-062, Brazil

Full list of author information is available at the end of the article
}

between renal supply and demand and ultimately promoting AKI [9].

Over time, different definitions of AKI have been proposed for cirrhotic patients [10]. In 2012, a universal definition of acute renal injury was proposed by the KDIGO group [11]. However, although this definition is widely applied in different populations, there are few validation studies of KDIGO in cirrhotic patients [2, 12], and such studies rarely consider the context of the emergency department [4].

In addition, an attempt to better describe and identify cirrhotic patients with AKI, is to implement a substratification of KDIGO stage 1 into 1a and $1 \mathrm{~b}$, with a creatinine value of $1.50 \mathrm{mg} / \mathrm{dL}$ as the discriminatory threshold [7].

(c) The Author(s). 2018 Open Access This article is distributed under the terms of the Creative Commons Attribution 4.0 International License (http://creativecommons.org/licenses/by/4.0/), which permits unrestricted use, distribution, and 
Such stratification proposes that those patients belonging to subgroup 1a would present a short-term mortality similar to the patients in the non-AKI group, which is different from those in subgroup $1 \mathrm{~b}$, who would present a higher odds ratio for mortality when compared to those in the non-AKI control group [2]. Another important tool is to evaluate the progression of AKI since patients who do not show improvement or stabilization of renal function will have a worse prognosis [13].

This study aimed to characterize a population of cirrhotic patients treated at the emergency department based on risk factors associated with worse prognosis for mortality and development of AKI. We also applied the KDIGO criteria for AKI within the first 7 days of hospitalization, testing the possible correlation between mortality and substratification of the KDIGO 1 group in stages $1 \mathrm{a}$ and $1 \mathrm{~b}$, and finally, looking for an association between progression of AKI with mortality in this population.

\section{Methods}

All hospitalizations from the Emergency Department of the São Paulo Hospital, a university hospital linked to the Federal University of São Paulo, Brazil, between March 2015 and February 2017, were retrospectively evaluated. The inclusion criteria were a clinical diagnosis of hepatic cirrhosis, age above 18 years and a minimum hospital stay of $48 \mathrm{~h}$. Exclusion criteria included renal and/or hepatic transplant patients, pregnant women and patients with chronic kidney disease who previously underwent dialysis. For those who were admitted to the emergency department more than one time within the specified period above, we only included data from the first admission. For the characterization and evaluation (incidence and mortality outcome) of AKI, the KDIGO 2012 criteria were applied, comparing peak creatinine and baseline creatinine (Fig. 1). Baseline creatinine was defined as the one prior to admission up to 3 months

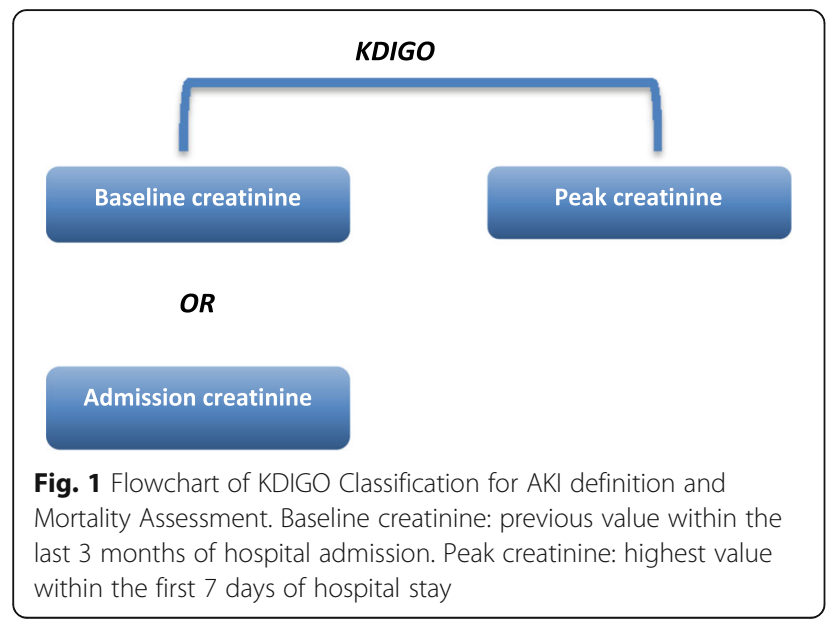

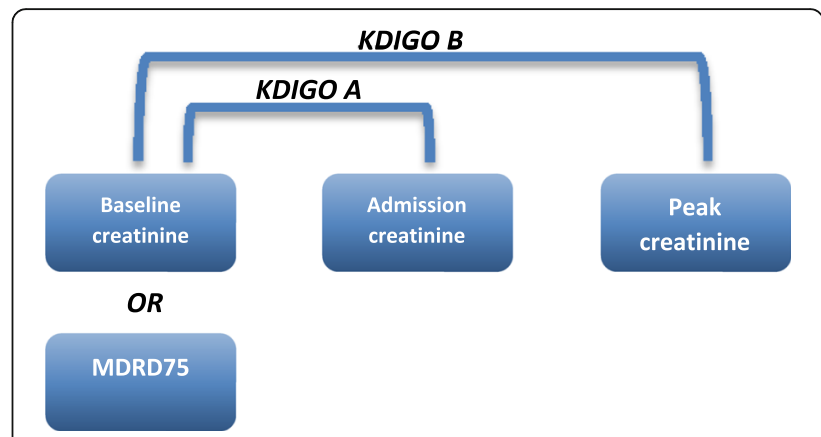

Fig. 2 Flowchart of KDIGO Classification for AKI Progression. Baseline creatinine: previous value within the last 3 months of hospital admission. MDRD 75: Calculated creatinine value considering an eGFR of $75 \mathrm{ml} / \mathrm{min} / 1.73 \mathrm{~m}^{2}$ using the MDRD formula. Peak creatinine: highest value within the first 7 days of hospital stay. Progressors defined if KDIGO B > KDIGO A

before hospitalization, which was obtained from the electronic medical record, or, in its absence, was considered to be the admission value, according to the guidance of the International Club of Ascites [14]. According to the common and widespread use in the literature, the final stage of AKI was defined by peak creatinine (the highest value obtained during the first 7 days of hospital admission) $[2,14,15]$. Diuresis data were not considered because of the difficulty of measuring diuresis in the emergency department, resulting in the absence of these data for most patients, and because it is not a very accurate measurement to evaluate kidney function in cirrhotic patients $[14,16,17]$.

For the analysis of the progression of AKI from admission to the first 7 days and its correlation with mortality,

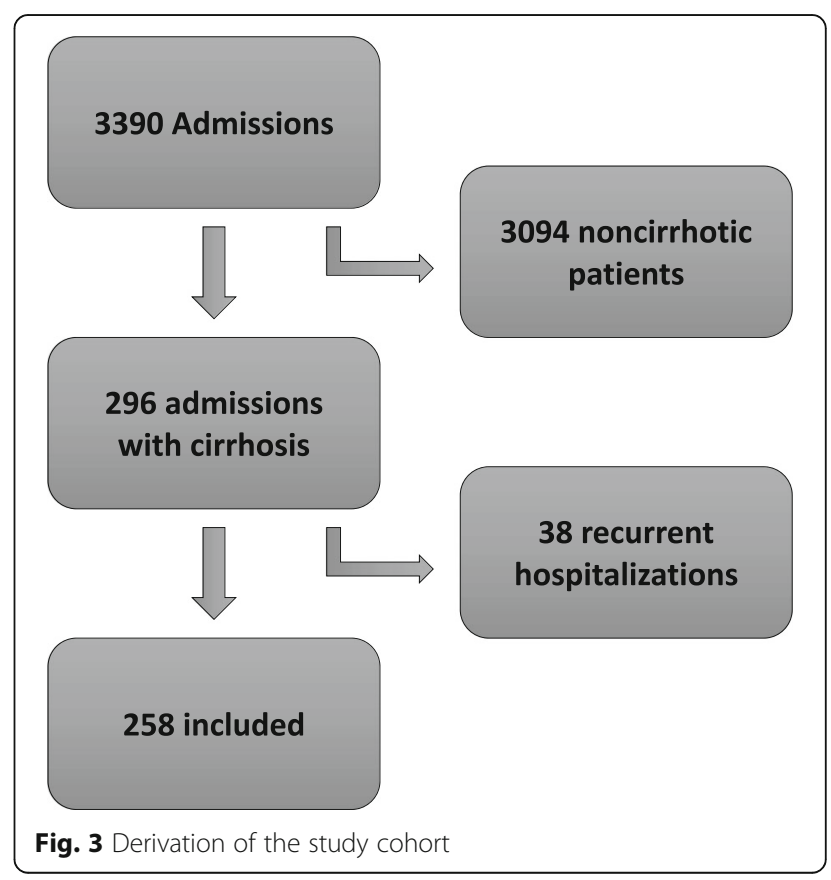


Table 1 Demographic, clinical and laboratory data among survivors and non-survivors

\begin{tabular}{|c|c|c|c|c|}
\hline & Total & Survivors & Non-survivors & $p$ \\
\hline Patients, \% & 258 & $185(71.7)$ & $73(28.4)$ & \\
\hline Age, years (median, IQR) & $59(52 ; 65)$ & $57.9(12.2)$ & $58.7(12.2)$ & 0.681 \\
\hline Gender, male / female (\%) & 185 (71.7) / 73 (28.3) & $130(70.3) / 55(75.3)$ & $55(29.7) / 18(24.7)$ & 0.447 \\
\hline \multicolumn{5}{|l|}{ Etiology, $n(\%)$} \\
\hline Alcohol & $125(48.4)$ & $93(50.3)$ & $32(43.8)$ & 0.407 \\
\hline Viral & $100(38.8)$ & $68(36.8)$ & $32(43.8)$ & 0.322 \\
\hline Non-viral and Non-alcohol & $54(20.9)$ & $40(21.6)$ & $14(19.2)$ & 0.736 \\
\hline Days of hospitalization (median, IQR) & $7(3 ; 13)$ & $6(3 ; 11)$ & $12(6 ; 23)$ & $<0.001$ \\
\hline ICU admission (\%) & $78(30.2)$ & $35(18.9)$ & $43(58.9)$ & $<0.001$ \\
\hline admission MELD score (median, IQR) & $18(14 ; 23)$ & $17(13 ; 22)$ & $19(16 ; 26)$ & 0.002 \\
\hline admission APACHE II (median, IQR) & $16(12 ; 22)$ & $15(12 ; 20)$ & $18(14 ; 23)$ & 0.015 \\
\hline admission MAP (mmHg), (median, IQR) & $89(75 ; 100)$ & $91(74 ; 102)$ & $84(76 ; 95)$ & 0.036 \\
\hline \multicolumn{5}{|l|}{ Comorbidities, $n$ (\%) } \\
\hline Hypertension & $114(44.2)$ & $88(47.6)$ & $26(35.6)$ & 0.095 \\
\hline Diabetes & $82(31.8)$ & $67(36.2)$ & $15(20.5)$ & 0.017 \\
\hline Smoking (present or past) & $69(26.7)$ & $46(24.9)$ & $23(31.5)$ & 0.279 \\
\hline Cancer & $57(22.1)$ & $32(17.3)$ & $25(34.2)$ & 0.004 \\
\hline Hepatocarcinoma & $41(70.7)$ & $24(72.7)$ & $17(68)$ & 0.775 \\
\hline Non-hepatocarcinoma & $17(29.3)$ & $9(27.3)$ & $8(32)$ & \\
\hline Heart failure & $26(10.1)$ & $20(10.8)$ & $6(8.2)$ & 0.649 \\
\hline \multicolumn{5}{|l|}{ Cause of hospitalization, n (\%) } \\
\hline Infection & $138(53.5)$ & $92(66.7)$ & $46(33.3)$ & 0.071 \\
\hline Non-infection & $120(46.5)$ & $93(77.5)$ & $27(22.5)$ & \\
\hline \multicolumn{5}{|l|}{$\mathrm{AKI}, n(\%)$} \\
\hline Yes & $139(53.9)$ & $80(57.6)$ & $59(42.4)$ & $<0.001$ \\
\hline No & $119(46.1)$ & $105(82.2)$ & $14(11.8)$ & \\
\hline \multicolumn{5}{|l|}{ Progression of AKI, $n(\%)$} \\
\hline Yes & $39(27.9)$ & $16(41)$ & $23(59)$ & $<0.001$ \\
\hline No & $101(72.1)$ & $77(76.2)$ & $24(23.8)$ & \\
\hline Baseline eGFR (ml/min/1.73m²) (median, IQR) & $57(35 ; 80)$ & $59(37 ; 82)$ & $52(31 ; 72)$ & 0.055 \\
\hline \multicolumn{5}{|l|}{ Laboratory } \\
\hline Hemoglobin, g/dL (mean, SD) & $11.2(2.75)$ & $11.2(2.7)$ & $11.1(2.8)$ & 0.894 \\
\hline Albumin, g/dL (mean, SD) & $2.9(0.6)$ & $3(0.6)$ & $2.7(0.6)$ & 0.008 \\
\hline Leucocytes, 1000/uL (median, IQR) & $8.8(5.7 ; 12.4)$ & $8.1(5.4 ; 11.0)$ & $10.7(7.3 ; 14.1)$ & $<0001$ \\
\hline Platelets, 1000/uL (median, IQR) & $126(80 ; 186)$ & $122(74 ; 180)$ & $143(94 ; 195)$ & 0.158 \\
\hline INR (median, IQR) & $1.4(1.2 ; 1.6)$ & $1.4(1.2 ; 1.6)$ & $1.5(1.3 ; 1.7)$ & 0.022 \\
\hline Total Bilirrubin, mg/dL (median, IQR) & $2.2(1.0 ; 4.7)$ & $1.7(0.8 ; 3.5)$ & $2.9(1.2 ; 7.6)$ & 0.002 \\
\hline Baseline Creatinine, mg/dL (median, IQR) & $1.04(0.80 ; 1.58)$ & $1.02(0.76 ; 1.50)$ & $1.10(0.87 ; 1.74)$ & 0.054 \\
\hline Admission Creatinine, mg/dL (median,IQR) & $1.40(0.85 ; 2.34)$ & $1.24(0.80 ; 2.31)$ & $1.61(0.96 ; 2.50)$ & 0.086 \\
\hline Peak Creatinine, mg/dL (median, IQR) & $1.9(1.01 ; 2.98)$ & $1.47(0.92 ; 2.48)$ & $2.86(1.93 ; 4.10)$ & $<0.001$ \\
\hline Sodium mEq/L (median, IQR) & $136(132 ; 139)$ & $137(133 ; 139)$ & $136(132 ; 139)$ & 0.197 \\
\hline Urea, mg/dL (median, IQR) & $61(34 ; 99)$ & $52(33 ; 89)$ & $76(38 ; 104)$ & 0.022 \\
\hline
\end{tabular}

AKI Acute Kidney Injury. MAP Mean Arterial Pressure. eGFR Estimated Glomerular Filtration Rate. MELD and APACHE II were obtained from admission data 
we performed a second classification of AKI according to the KDIGO criteria, comparing admission creatinine to the previous creatinine of hospitalization (baseline creatinine). Because we had no previous creatinine value for 109 patients (42\% of total), we used the back calculation of creatinine considering a MDRD of $75 \mathrm{ml} / \mathrm{min} / 1.73 \mathrm{~m}^{2}$ (MDRD-75) for these patients [16]. Both classifications were compared, admission and peak, in order to analyze the progression of AKI [18]. Progression of AKI was defined as the increase from lower stages of AKI to higher stages, such as AKI stage 1 to stage 2 or 3 or from stage 2 to stage 3 during the first week or until discharge [13] (Fig. 2).

Statistical analysis was performed with SPSS statistics software version 23.0 for Windows. Quantitative variables were represented by mean and standard deviation

Table 2 Demographic, clinical and laboratory data among AKI and non-AKI groups

\begin{tabular}{|c|c|c|c|c|}
\hline & Total & Non-AKI & AKI & $p$ \\
\hline Patients, \% & 258 & $119(46.1)$ & $139(53.9)$ & \\
\hline Age, years (median, IQR) & $59(52 ; 65)$ & $59(52 ; 66)$ & $60(53 ; 65)$ & 0.630 \\
\hline Gender, male / female (\%) & $185(71.7) / 73(28.3)$ & $83(69.7)$ / 36 (30.3) & $102(73.4) / 37(26.6)$ & 0.580 \\
\hline \multicolumn{5}{|l|}{ Etiology, n (\%) } \\
\hline Alcohol & $125(48.4)$ & $55(46.2)$ & $70(50.4)$ & 0.534 \\
\hline Viral & $100(38.8)$ & $41(34.5)$ & $59(42.4)$ & 0.202 \\
\hline Non-viral and Non-alcohol & $54(20.9)$ & $30(25.2)$ & $24(17.3)$ & 0.127 \\
\hline Days of hospitalization (median, IQR) & $7(3 ; 13)$ & & & \\
\hline ICU admission (\%) & $78(30.2)$ & $19(16)$ & $59(42.4)$ & $<0.001$ \\
\hline admission MELD score (median, IQR) & $18(14 ; 23)$ & $16(11 ; 19)$ & $19(16 ; 25)$ & $<0.001$ \\
\hline admission APACHE II (median, IQR) & $16(12 ; 22)$ & $14(11 ; 18)$ & $19(14 ; 23)$ & $<0.001$ \\
\hline admission MAP (mmHg), (median, IQR) & $89(75 ; 100)$ & $89(76 ; 100)$ & $87(74 ; 100)$ & 0.679 \\
\hline \multicolumn{5}{|l|}{ Comorbidities, $n$ (\%) } \\
\hline Hypertension & $114(44.2)$ & $51(42.9)$ & $63(45.3)$ & 0.708 \\
\hline Diabetes & $82(31.8)$ & $36(30.3)$ & $46(33.1)$ & 0.688 \\
\hline Smoking (present or past) & $69(26.7)$ & $30(25.2)$ & $39(28.1)$ & 0.673 \\
\hline Cancer & $57(22.1)$ & $26(21.8)$ & $31(22.3)$ & 1 \\
\hline Hepatocarcinoma & $41(70.7)$ & $19(70.4)$ & $22(71)$ & 1 \\
\hline Non-hepatocarcinoma & $17(29.3)$ & $8(29.6)$ & $9(29)$ & \\
\hline Heart failure & $26(10.1)$ & $11(9.2)$ & $15(10.8)$ & 0.836 \\
\hline \multicolumn{5}{|l|}{ Cause of hospitalization, $n(\%)$} \\
\hline Infection & $138(53.5)$ & $52(37.7)$ & $86(62.3)$ & 0.004 \\
\hline Non-infection & $120(46.5)$ & $67(55.8)$ & $53(44.2)$ & \\
\hline Baseline eGFR (ml/min/1.73m²) (median, IQR) & $57(35 ; 80)$ & $66(35 ; 89)$ & $56(35 ; 73)$ & 0.073 \\
\hline \multicolumn{5}{|l|}{ Laboratory } \\
\hline Hemoglobin, g/dL (mean, SD) & $11.2(2.75)$ & $11.3(2.72)$ & $11.1(2.78)$ & 0.493 \\
\hline Albumin, g/dL (mean, SD) & $2.9(0.6)$ & $2.9(0.6)$ & $2.8(0.6)$ & 0.070 \\
\hline Leucocytes, 1000/uL (median, IQR) & $8.8(5.7 ; 12.4)$ & $7.7(5.2 ; 11)$ & $10(6.7 ; 13.5)$ & 0.001 \\
\hline Platelets, 1000/uL (median, IQR) & $126(80 ; 186)$ & $108.5(70.5 ; 174.5)$ & $137(88 ; 192)$ & 0.036 \\
\hline INR (median, IQR) & $1.4(1.2 ; 1.6)$ & $1.4(1.2 ; 1.6)$ & $1.5(1.3 ; 1.7)$ & 0.009 \\
\hline Total Bilirrubin, mg/dL (median, IQR) & $2.2(1.0 ; 4.7)$ & $2(0.8 ; 4)$ & $2(1 ; 4.6)$ & 0.370 \\
\hline Baseline Creatinine, mg/dL (median, IQR) & $1.04(0.80 ; 1.58)$ & $0.96(0.70 ; 1.56)$ & $1.05(0.85 ; 1.59)$ & 0.081 \\
\hline Admission Creatinine, mg/dL (median,IQR) & $1.40(0.85 ; 2.34)$ & $0.98(0.72 ; 1.60)$ & $1.80(1.13 ; 2.77)$ & $<0.001$ \\
\hline Peak Creatinine, mg/dL (median, IQR) & $1.9(1.01 ; 2.98)$ & $0.99(0.75 ; 1.56)$ & $2.55(1.93 ; 3.85)$ & $<0.001$ \\
\hline Sodium (median, IQR) & $136(132 ; 139)$ & $137(133 ; 140)$ & $136(132 ; 139)$ & 0.078 \\
\hline Urea, mg/dL (median, IQR) & $61(34 ; 99)$ & $39(27 ; 70)$ & $78(46 ; 108)$ & $<0.001$ \\
\hline
\end{tabular}


if the distribution was normal (Kolmogorov-Smirnov test) and were compared by Student's T test. When a nonnormal distribution was characterized, median and interquartile range values were expressed, and the comparison was tested by the Wilcoxon test. Categorical variables were compared by the $x^{2}$ test (or Fischer exact test, when applicable). Possible risk factors for mortality that were identified in the univariate analysis with $p$ value $<0.1$ were included in models of logistic regression analysis. The data were presented as odds ratios and 95\% confidence intervals. Values of $p<0.05$ (2-tailed) were considered statistically significant.

Regarding the variables with missing data, we did not have previous creatinine values of 109 patients, as previously mentioned, and we did not have albumin values of 31 patients (12\%). For the missing albumin data, we used the multiple imputation method to perform the necessary analysis.

This study was approved by the Ethics in Research Committee of the Federal University of São Paulo, and formal informed consent was waived because of the observational nature of the study.

\section{Results}

The population studied included 258 patients (Fig. 3). From 3390 hospitalizations at the University Hospital Emergency Department, 3094 were noncirrhotic patients. Among the remaining 296 cirrhotic patients, 38 had recurrent hospitalizations, and only the first admission was considered for statistical analysis.

Clinical, laboratory, and demographic characteristics of patients included in the study are presented in Tables 1 and 2. These tables include the main comorbidities of patients in descending order of prevalence, mean length of hospital stay, ICU admission rate, APACHE II score from admission, MELD score from admission and admission mean arterial pressure (MAP). Regarding the etiology of cirrhosis, it was classified in three groups (viral, alcoholic and nonviral non-alcoholic), according to the two main causes of cirrhosis worldwide. The reason for admission to the emergency room was similarly divided into two groups, considering both infectious and noninfectious causes.

The overall mortality rate was $28.4 \%$, with no significant difference in relation to the mean age $(p=$ $0.681)$, sex $(p=0.447)$, the etiology of cirrhosis (alcoholic $p=0.407$, viral $p=0.322$, nonviral and non-alcoholic $p=0.736)$ or hospitalization due to infectious causes $(p=0.071)$. However, the nonsurvivor group had the highest median APACHE II admission (18 vs $15 p=0.015$ ), the highest median MELD score (19 vs $17 p=0.002)$ and the highest ICU admission rate $(58.9 \%$ vs $18.9 \% p=<0.01)$. Among the comorbidities presented, patients with cancer presented higher mortality when compared to noncancer patients $(34.2 \%$ vs $17.3 \% p=0.004)$, but this difference was not statistically significant when the primary site was evaluated as hepatocarcinoma $(p=0.775)$ versus nonhepatocarcinoma tumors.

In multivariate analysis, variables with $p<0.1$ according to univariate analysis were included in the model. Independent risk factors for in-hospital mortality are shown in Table 3.

When the criteria for AKI were applied for evaluation related to the first 7 days, 139 (53.9\%) patients presented AKI: 55 (39.5\%) patients with KDIGO 1, 35

Table 3 Logistic Regression - Risk Factors for In-Hospital Mortality

\begin{tabular}{|c|c|c|c|}
\hline Variable & OR & $95 \% \mathrm{Cl}$ & $p$ \\
\hline \multicolumn{4}{|l|}{ MODEL 1} \\
\hline AKI & 4.66 & $1.94-11.17$ & $<0.001$ \\
\hline Cancer & 3.94 & $1.74-8.89$ & $<0.001$ \\
\hline Length of stay in hospital & 1.07 & $1.03-1.10$ & $<0.001$ \\
\hline Leukocytes & 1.08 & $1.01-1.15$ & 0.016 \\
\hline Diabetes & 0.31 & $0.11-0.80$ & 0.016 \\
\hline MAP & 0.98 & $0.96-1.00$ & 0.126 \\
\hline Age & 1.02 & $0.98-1.05$ & 0.195 \\
\hline MELD & 1.04 & $0.97-1.11$ & 0.247 \\
\hline APACHE ॥ & 0.97 & $0.88-1.05$ & 0.427 \\
\hline Suspected infection & 0.76 & $0.35-1.63$ & 0.483 \\
\hline Baseline eGFR & 1.07 & $0.77-1.47$ & 0.694 \\
\hline Male Sex & 1.16 & $0.51-2.59$ & 0.726 \\
\hline Hypertension & 0.89 & $0.37-2.09$ & 0.788 \\
\hline Urea & 0.99 & $0.98-1.01$ & 0.868 \\
\hline \multicolumn{4}{|l|}{ MODEL 2} \\
\hline Progression of AKI & 12.05 & $3.29-44.07$ & $<0.001$ \\
\hline Cancer & 10.27 & $2.73-38.47$ & $<0.001$ \\
\hline Age & 1.08 & $1.02-1.14$ & 0.006 \\
\hline MELD & 1.15 & $1.03-1.26$ & 0.006 \\
\hline Length of stay in hospital & 1.08 & $1,02-1,13$ & 0.007 \\
\hline Urea & 1.01 & $0.99-1.02$ & 0.073 \\
\hline MAP & 0.98 & $0.95-1.00$ & 0.090 \\
\hline APACHE ॥ & 0.93 & $0.82-1.05$ & 0.240 \\
\hline Baseline eGFR & 0.81 & $0.55-1.17$ & 0.273 \\
\hline Hypertension & 0.53 & $0.14-1.87$ & 0.322 \\
\hline Leukocytes & 1.04 & $0.95-1.13$ & 0.367 \\
\hline Male Sex & 1.26 & $0.38-4.10$ & 0.702 \\
\hline Diabetes & 0.89 & $0.26-2.99$ & 0.852 \\
\hline Suspected infection & 1.09 & $0.34-3.46$ & 0.882 \\
\hline
\end{tabular}

We considered the following units: per day for Length of stay in hospital, per year for Age, per $1 \mathrm{mg} / \mathrm{dL}$ for Urea, per $1 \mathrm{mmHg}$ for MAP, per $1 \mathrm{ml} / \mathrm{min} /$ $1.73 \mathrm{~m}^{2}$ for eGFR, per $1 \times 10^{3} / \mu \mathrm{L}$. AKI Acute Kidney Injury. MAP Mean Arterial Pressure. eGFR Estimated Glomerular Filtration Rate. MELD and APACHE II were obtained from admission data 
(25.1\%) with KDIGO 2 and 49 (35.2\%) with KDIGO 3. Of the 49 patients with KDIGO 3, 18 (36.7\%) required dialysis treatment. Among the patients with AKI, a higher admission rate in the ICU (42.4\% vs $16 \%)$, higher APACHE II value (19 vs 14), higher MELD score (19 vs 16) and a higher incidence of infectious causes $(62.3 \%$ vs. $37.7 \%$ ) when compared to the non-AKI group were observed. There was no difference in relation to the etiology of cirrhosis or the presence of comorbidities between the groups. The overall mortality of the AKI group was $42.4 \%$, and it was $11.8 \%$ in the non-AKI group.

The AKI subgroups of the KDIGO classification and the relationship with mortality are presented in Fig. 4 and Table 4 . Within the KDIGO 1 group, 28 fulfill only elevation in creatinine $\geq 0.3 \mathrm{mg} / \mathrm{dL}$ in $48 \mathrm{~h}$; the other 27 patients matched the criteria of elevation of $1.5 \times$ baseline creatinine at 7 days. Among these patients, 16 (29.1\%) were KDIGO 1a and 39 (70.9\%) KDIGO 1B. Differences in mortality with statistical significance were observed for the groups 2 and 3 when compared to group without AKI. In the analysis of KDIGO 1 subgroups, mortality was $12.5 \%$ and $33.3 \%$ for $1 \mathrm{a}$ and $1 \mathrm{~b}$, respectively, with significance only for subgroup $1 \mathrm{~b}$. There was no significant difference in mortality between the KDIGO 2 and 3 groups. The final model was adjusted for age, sex, hypertension, diabetes, APACHE II and MELD scores.

Logistic regression methods are shown in 2 models to mitigate collinearity between AKI admission diagnosis and AKI progression status (Table 3) - MODEL 1 consider admission criteria of AKI plus all covariates that presents with $p<0.1$ in univariate analysis. MODEL 2 shows criteria of Progression of AKI plus all covariates that present with $\mathrm{p}<0.1$ in univariate analysis. In model 1 , admission criteria of AKI, cancer diagnosis, length of stay in hospital, and leukocyte count (per 103 increase) are shown as risk factors for mortality. About model 2, the risk factors for mortality present as Progression of AKI, cancer diagnosis, Age (per year), MELD score at admission and length of stay in hospital.

Finally, the progression of AKI occurred in 39 patients (27.9\% of those with AKI). In those who progressed, mortality was $59 \%$ and was $23.8 \%$ in the nonprogression group $(p<0.001)$ (Table 4$)$.

\section{Discussion}

This study presented the evaluation of 258 cirrhotic patients admitted to an emergency unit. In general, the mortality rate $(28.4 \%)$ was similar to that reported for similar cohorts $[1,6-8,12,15]$. The most common etiology was similar to that of national and international cohorts [17], with alcoholic cirrhosis being the most common followed by viral etiology (mainly secondary to hepatitis C). Due to the unavailability of the level of ascites in electronic records of some patients and the heterogeneous classification of hepatic encephalopathy, a Child-Pugh-Turcotte classification was not possible, but we inferred from clinical and laboratory data that the majority of patients would be classified as having at least Child B liver cirrhosis with a mortality similar to that reported in the literature [8].

This investigation has shown that patients with AKI in progression have an increasing mortality according to the classification of renal impairment (Fig. 4), which reinforces the need for a temporal and progressive evaluation of renal function. In addition, in this population, the presence of progression of AKI and peak creatinine in the first 7 days of admission presented better performance when compared to the isolated creatinine value of entry, regarding mortality. Surprisingly, the baseline eGFR prior to hospital admission did not present as a risk factor for mortality or acute kidney injury during hospitalization, as widely established in the

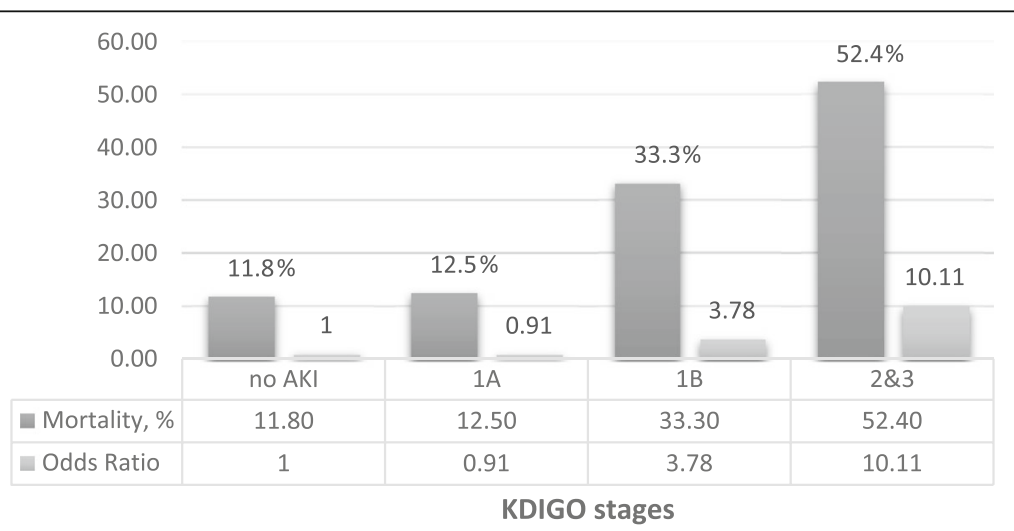

Fig. 4 Logistic regression considering the groups with statistical difference between each other (1a, 1b, 2 and 3). Adjusted for age, sex, hypertension, diabetes, APACHE II score and MELD score. No AKI is the reference group (Odds Ratio = 1). AKI - Acute Kidney Injury. KDIGO stages and Mortality Analysis 
Table 4 AKI Stages and Mortality Outcome

\begin{tabular}{|c|c|c|c|c|c|c|c|c|}
\hline \multirow[t]{2}{*}{ Stages of AKI } & \multirow[t]{2}{*}{ Total } & \multirow{2}{*}{$\begin{array}{l}\text { Mortality, } \\
\%\end{array}$} & \multicolumn{3}{|c|}{ Unadjusted } & \multicolumn{3}{|c|}{ Adjusted $^{\mathrm{b}}$} \\
\hline & & & $\mathrm{OR}$ & IC 95\% & $p$ & $\mathrm{OR}$ & IC 95\% & $p$ \\
\hline$\overline{n o} A K l^{a}$ & 119 & 11.8 & 1 & & & 1 & & \\
\hline AKI & 139 & 42.2 & & & & & & \\
\hline KDIGO 1 & 55 & 27.3 & 2.81 & $1.24-6.35$ & 0.013 & & & \\
\hline $1 a$ & 16 & 12.5 & 1.07 & $0.22-5.21$ & 0.932 & 0.91 & $0.18-4.60$ & 0.916 \\
\hline $1 b$ & 39 & 33.3 & 3.75 & $1.57-8.93$ & 0.003 & 3.78 & $1.47-9.70$ & 0.006 \\
\hline KDIGO 2 and 3 & 84 & 52.4 & & & & 10.11 & $4.36-23.43$ & $<0.001$ \\
\hline KDIGO 2 & 35 & 40.0 & 5.00 & $2.08-12.01$ & $<0.001$ & & & \\
\hline KDIGO 3 & 49 & 61.2 & 11.84 & $5.31-26.37$ & $<0.001$ & & & \\
\hline
\end{tabular}

${ }^{\mathrm{a}}$ Reference group. ${ }^{\mathrm{b}}$ Adjusted for age, sex, hypertension, diabetes, APACHE II score and MELD score. AKI, acute kidney injury

literature of noncirrhotic patients [18]; however, there are already clinical trials in cirrhotic patients with results similar to our study [6].

Multivariate analysis showed that both AKI diagnosis at admission and AKI Progression criteria are major risk factors for mortality; this information suggests that cirrhotic patients with less severe AKI (KDIGO 1) need a special approach and structured care. Surprisingly, the APACHE II score lost its power of discrimination on both models in multivariate analysis. Another study found similar results [19] and presented a possible explanation that the Apache II score lacks a liver-specific prognostic factor in its calculator, so it is probable that the Apache II score will lose its strength when compared with another specific variables. In model 1 , the MELD score lost its ability to predict mortality risk probably because of collinearity between the admission creatinine and calculated admission MELD.

As shown in Table 4, the presence of AKI KDIGO 1b was shown to be a risk factor for mortality, different from the presence of AKI KDIGO 1a. This fact corroborates the subclassification proposed by the International Club of Ascites [13], which reinforces that small elevations in the value of creatinine, especially when they exceed $1.50 \mathrm{mg} / \mathrm{dL}$, have a great impact on the morbidity and mortality of patients with cirrhosis.

No significant difference in mortality was found between the stages without AKI and KDIGO 1a, and the KDIGO stages 2 and 3. It is possible to identify three major progressive mortality groups: KDIGO 1a, KDIGO $1 \mathrm{~b}$ and KDIGO 2/3, with the prognosis of the first group comparable to the absence of AKI, reinforcing previous data [15].

There are several limitations of our study. Although the present investigation was based on a retrospective cohort, it presents an analysis of a considerably large number of patients, regarding this specific population of cirrhotic patients in an emergency department, which ought to be considered innovative in the literature. Due to missing clinical data, we were not able to achieve a Child-Pugh classification or include the etiology of AKI. Since we designed this study to assess only the first week in the hospital, we did not evaluate the occurrence of late AKI (after 7 days). Another limitation is the lack of data on AKI duration, since patients who improve within $48 \mathrm{~h}$ may represent a phenotype of AKI with a better prognosis. Final limitation is the possible misclassification of chronic kidney disease as AKI when analyzing progression of AKI, since those patients without previous creatinine value were considered as having a eGFR of $75 \mathrm{ml} / \mathrm{min} / 1.73 \mathrm{~m}^{2}$.

\section{Conclusions}

According to the data presented above, a single measure of creatinine is not enough in this population, as this paper reinforces the need for meticulous follow-up of the renal function of patients with hepatic cirrhosis hospitalized in an emergency unit, in view of the correlation of renal function with clinical outcomes. In addition, in agreement with the current literature, the data reinforce the need for subclassification of KDIGO 1 in cirrhotic patients, demonstrating that patients with acute renal injury and creatinine greater than $1.5 \mathrm{mg} / \mathrm{dL}$ present a worse clinical outcome.

\section{Abbreviations \\ AKl: Acute Kidney Injury; eGFR: Estimated Glomerular Filtration Rate; ICU: Intensive Care Unit; KDIGO: Kidney Disease: Improving Global Outcomes; MAP: Mean Arterial Pressure; MDRD: Modification of Diet in Renal Disease Formula for eGFR}

\section{Acknowledgements}

We thank Dr. Daniel Ribeiro da Rocha, Dr. Sarah Pontes de Barros Leal, Dr. Klaus Nunes Ficher and Dr. Raphael Costa Bandeira de Melo for their contributions.

Availability of data and materials

The datasets used and/or analyzed during the current study are available from the corresponding author upon reasonable request. 


\section{Authors' contributions}

PRGL and AFTG designed the study. PRGL and WSCP contributed to the implementation of the research, data collection, statistical work, to the analysis of the results and to the writing of the manuscript. WSCP designed the tables and figures. AFTG, CFGM and MCB verified the analytical methods and aided in interpreting the results. All authors discussed the results and contributed to the final manuscript. All authors read and approved the final manuscript

\section{Ethics approval and consent to participate}

This study was approved by the Ethics in Research Committee of the Federal University of São Paulo (protocol number 1478/2016).

\section{Consent for publication}

Not applicable.

\section{Competing interests}

The authors declare that they have no competing interests.

\section{Publisher's Note}

Springer Nature remains neutral with regard to jurisdictional claims in published maps and institutional affiliations.

\section{Author details}

'Discipline of Nephrology, Federal University of São Paulo, Rua Botucatu, 591 - $15^{\circ}$ andar - Cj153 - Vila Clementino, São Paulo, SP 04023-062, Brazil.

${ }^{2}$ Discipline of Medicine of Urgency and Evidence-Based Medicine from the Department of Medicine, Federal University of São Paulo, Rua Napoleão de Barros, 865 - Vila Clementino, São Paulo, SP 04023-090, Brazil.

Received: 1 April 2018 Accepted: 27 September 2018

Published online: 20 October 2018

\section{References}

1. Alsultan MA, Alrshed RS, Aljumah AA, Baharoon SA, Arabi YM, Aldawood AS In-hospital mortality among a cohort of cirrhotic patients admitted to a tertiary hospital. Saudi J Gastroenterol. 2011;17(6):387-90.

2. Piano S, Rosi S, Maresio G, Fasolato S, Cavallin M, Romano A, et al. Evaluation of the acute kidney injury network criteria in hospitalized patients with cirrhosis and ascites. J Hepatol. 2013;59(3):482-9.

3. Wong F, Bernardi M, Balk R, Christman B, Moreau R, Garcia-Tsao G, et al. Sepsis in cirrhosis: report on the 7th meeting of the international ascites Club. Gut. 2005;54(5):718-25.

4. Ximenes RO, Farias AQ, Scalabrini Neto A, Diniz MA, Kubota GT, MMA-A I, et al. Patients with cirrhosis in the ED: early predictors of infection and mortality. Am J Emerg Med. 34(1):25-9.

5. Pant C, Olyaee M, Gilroy R, Pandya PK, Olson JC, Oropeza-Vail M, et al. Emergency department visits related to cirrhosis: a retrospective study of the Nationwide emergency department sample 2006 to 2011. Medicine. 2015:94(1):e308.

6. Belcher JM, Garcia-Tsao G, Sanyal AJ, Bhogal H, Lim JK, Ansari N, et al. Association of AKI with mortality and complications in hospitalized patients with cirrhosis. Hepatology (Baltimore), Md. 2013;57(2):753-62.

7. Fagundes C, Barreto R, Guevara M, Garcia E, Sola E, Rodriguez E, et al. A modified acute kidney injury classification for diagnosis and risk stratification of impairment of kidney function in cirrhosis. J Hepatol. 2013;59(3):474-81.

8. Scott RA, Austin AS, Kolhe NV, Mclntyre CW, Selby NM. Acute kidney injury is independently associated with death in patients with cirrhosis. Frontline gastroenterology. 2013;4(3):191-7.

9. Ginès P, Schrier RW. Renal failure in cirrhosis. N Engl J Med. 2009;361(13): 1279-90.

10. Sherman DS, Fish DN, Teitelbaum I. Assessing renal function in cirrhotic patients: problems and pitfalls. Am J Kidney Dis. 2003;41(2):269-78.

11. Nadim MK, Kellum JA, Davenport A, Wong F, Davis C, Pannu N, et al. Hepatorenal syndrome: the 8(th )international consensus conference of the acute Dialysis quality initiative (ADQI) group. Crit Care. 2012;16(1):R23-R.

12. Pan H-C, Chien Y-S, Jenq C-C, Tsai M-H, Fan P-C, Chang C-H, et al. Acute kidney injury classification for critically ill cirrhotic patients: a comparison of the KDIGO, AKIN, and RIFLE classifications. Sci Rep. 2016;6:23022.
13. Belcher JM, Garcia-Tsao G, Sanyal AJ, Thiessen-Philbrook H, Peixoto AJ, Perazella MA, et al. Urinary biomarkers and progression of AKI in patients with cirrhosis. Clin J Am Soc Nephrol. 2014;9(11):1857-67.

14. Angeli $P$, Ginès $P$, Wong $F$, Bernardi $M$, Boyer TD, Gerbes $A$, et al. Diagnosis and management of acute kidney injury in patients with cirrhosis: revised consensus recommendations of the International Club of Ascites. J Hepatol. 62(4):968-74.

15. Huelin P, Piano S, Sola E, Stanco M, Sole C, Moreira R, et al. Validation of a staging system for acute kidney injury in patients with cirrhosis and association with acute-on-chronic liver failure. Clin Gastroenterol Hepatol. 2017:15(3):438-45.e5.

16. Angeli $P$, Gines $P$, Wong F, Bernardi M, Boyer TD, Gerbes $A$, et al. Diagnosis and management of acute kidney injury in patients with cirrhosis: revised consensus recommendations of the International Club of Ascites. J Hepatol. 2015:62(4):968-74

17. Wong F, Nadim MK, Kellum JA, Salerno F, Bellomo R, Gerbes A, et al. Working party proposal for a revised classification system of renal dysfunction in patients with cirrhosis. Gut. 2011;60(5):702-9.

18. Wang HE, Jain G, Glassock RJ, Warnock DG. Comparison of absolute serum creatinine changes versus kidney disease: improving global outcomes consensus definitions for characterizing stages of acute kidney injury. Nephrol Dial Transplant. 2013:28(6):1447-54.

19. Fang JT, Tsai MH, Tian YC, Jenq CC, Lin CY, Chen YC, et al. Outcome predictors and new score of critically ill cirrhotic patients with acute renal failure. Nephrol Dial Transplant. 2008;23(6):1961-9.
Ready to submit your research? Choose BMC and benefit from:

- fast, convenient online submission

- thorough peer review by experienced researchers in your field

- rapid publication on acceptance

- support for research data, including large and complex data types

- gold Open Access which fosters wider collaboration and increased citations

- maximum visibility for your research: over $100 \mathrm{M}$ website views per year

At BMC, research is always in progress.

Learn more biomedcentral.com/submission 